\title{
Evidence for an environmental effect in the aetiology of insulin dependent diabetes in a transmigratory population
}

\author{
H J Bodansky, A Staines, C Stephenson, D Haigh, R Cartwright
}

\begin{abstract}
Objective - To examine whether children of families - moving from an area of low incidence of childhood diabetes to one which is higher show a corresponding rise in disease incidence.
\end{abstract}

Design-Disease incidence study over 12 years.

Setting-Bradford District Metropolitan Council area.

Subjects-All subjects aged 0-16 years resident within the study area.

Main outcome measures-The incidences of childhood diabetes in Asian and non-Asian families.

Results-The incidence of diabetes in Asian children increased from $3 \cdot 1 / 100000$ per year in $1978-81$ to $11 \cdot 7 / 100000$ per year in $1988-90\left(\chi^{2}\right.$ for trend $=4.95, \mathrm{df}=1, \mathrm{p}=0.026$ ) whereas that for other children remained constant at $10 \cdot 5 / 100000$ per year. Over the entire study period rates were lower in Asian females (4.9/100000 per year) than in Asian males $(8 \cdot 8 / 100000$ per year) whereas the reverse was true for other children (males $\mathbf{9 \cdot 2 / 1 0 0 0 0 0 ~ p e r ~ y e a r ; ~}$ females $12 \cdot 0 / 100000$ per year) (test for common odds ratio: $\chi^{2}=3.81, \mathrm{df}=1, \mathrm{p}=0.052$ ).

Conclusions-Offspring of this transmigratory population had a rising incidence of childhood diabetes which was approaching that of the indigenous population. The data provide strong evidence for an environmental effect in the aetiology of insulin dependent diabetes.

\section{Introduction}

The cause of insulin dependent diabetes in children is incompletely understood. However, observations from family and identical twin studies have shown that the condition has a genetic component. ${ }^{12}$ Several loci are involved, the strongest probably involving the HLA-DR/DQ histocompatibility complex on the short arm of chromosome $6 .{ }^{3}$ The condition does not have a completely genetic basis, however, because the concordance rate for diabetes in identical twins is only about $30 \% .^{2}$ Thus it has been postulated that the remaining element in the aetiology must be environmental. ${ }^{4}$ Despite this statistical inference of such an effect, it has remained unproved that it exists and its nature has always been speculative. A variety of agents, including viral infections and toxins, have been suggested, although despite much circumstantial evidence no single environmental insult has emerged as a leading cause of diabetes in the majority of childhood cases. $^{56}$

An alternative approach to the examination of an environmental effect in disease aetiology involves study of transmigratory populations. A well known example is the appearance of coronary artery disease in Japanese migrants from their native low risk area to Hawaii and the west coast of America, where this condition is common. Insulin dependent diabetes shows striking geographical variations, with an increase in incidence from southern to northern Europe, and is quite rare in Japan. ${ }^{8}$ The Indian subcontinent is also said to have an extremely low incidence of juvenile insulin dependent diabetes. ${ }^{9}$ However, this condition can occur in migrant Asian children, and in a cohort living in the United Kingdom the typical clinical, genetic, and immunological features of insulin dependent diabetes in the indigenous population were seen. ${ }^{10}$

Over the past 30 years many Asian families from Pakistan have migrated to the Bradford, West Yorkshire, area, whose children have now been born in the United Kingdom. This unique transmigratory population has moved from an area of extremely low incidence of childhood diabetes to one which is higher. If an environmental effect plays a part in childhood diabetes we should see a rising incidence of the condition in United Kingdom born Asian children. The aim of this study was to see if there was such an effect.

\section{Methods}

The data presented in this paper come from an ongoing diabetes incidence register for the Yorkshire Regional Health Authority. The data were collected retrospectively and pertained to all subjects aged under 17 and resident within the Yorkshire region boundaries at the time of diagnosis. In the United Kingdom childhood diabetes is usually treated from diagnosis by specialist hospital paediatricians. The ascertainment was validated by cross reference with a $10 \%$ sample of general practices in the region; no further cases resident in Bradford at diagnosis were identified. Cases meeting these criteria for ketosis prone insulin dependent diabetes were also sought from the districts and hospitals surrounding the Yorkshire region to ensure completeness of ascertainment for children resident or treated outside the region but diagnosed while resident within it.

The study area comprised the Bradford District Metropolitan Council area. Demographic details concerning age and ethnic origin for 1981-90 were obtained from the Bradford District Metropolitan Council and a population estimate for 1978 to 1980 derived from these by using the population figures from the 1971 United Kingdom census and birth rate data provided by Bradford District Metropolitan Council (1966-90) by linear interpolation. In $1981,11 \%$ of the total Bradford population was of Asian origin, as were $25 \%$ of subjects aged under 16. Almost all children with diabetes in the Bradford area are under the care of one paediatrician at one centre (DH). For this study all known United Kingdom born children in the district were included.

Statistical analysis was carried out by MantelHaenszel analysis, Poisson regression, and $\chi^{2}$ tests for trend. Genstat 5 was used for all analyses. ${ }^{11}$

\section{Results}

A total of 151 children with diabetes who fulfilled the inclusion criteria were ascertained. Of these, 26 were of Asian origin. Their families had come to the United Kingdom from Pakistan (22 cases), India (three), and India/Tanzania (one).

In the first four years of the study (1978-81) only 
TABLE I - Yearly incidence (per 100000 per year) of insulin dependent diabetes in Asian and non-Asian children in Bradford from 1978 to 1990

\begin{tabular}{|c|c|c|c|c|}
\hline \multirow[b]{2}{*}{ Year } & \multicolumn{2}{|c|}{ Non-Asians } & \multicolumn{2}{|c|}{ Asians } \\
\hline & No of cases & Rate & No of cases & Rate \\
\hline 1978 & 12 & $12 \cdot 07$ & 0 & 0 \\
\hline 1979 & 10 & $10 \cdot 21$ & 1 & $4 \cdot 26$ \\
\hline 1980 & 15 & $15 \cdot 56$ & 1 & 4.06 \\
\hline 1981 & 9 & $9 \cdot 45$ & 1 & 3.94 \\
\hline 1982 & 6 & $6 \cdot 42$ & 0 & 0 \\
\hline 1983 & 6 & $6 \cdot 55$ & 3 & 10.63 \\
\hline 1984 & 14 & $15 \cdot 54$ & 2 & 6.74 \\
\hline 1985 & 10 & $11 \cdot 31$ & 1 & $3 \cdot 23$ \\
\hline 1986 & 5 & $5 \cdot 74$ & 1 & $3 \cdot 12$ \\
\hline 1987 & 7 & 8.07 & 4 & $12 \cdot 21$ \\
\hline 1988 & 13 & $15 \cdot 04$ & 3 & 8.95 \\
\hline 1989 & 12 & 13.88 & 4 & $11 \cdot 70$ \\
\hline 1990 & 6 & 6.94 & 5 & $14 \cdot 28$ \\
\hline
\end{tabular}

TABLE II-Incidences (per 100000 per year) for males and females of insulin dependent diabetes in Asian and non-Asian children

\begin{tabular}{lcclllr}
\hline & \multicolumn{3}{c}{ Asian } & & \multicolumn{2}{c}{ Non-Asian } \\
\cline { 2 - 3 } \cline { 5 - 6 } Sex & No & Rate & & No & Rate \\
\hline Male & 17 & $8 \cdot 8$ & & 56 & $9 \cdot 2$ \\
Female & 9 & 4.9 & & 69 & $12 \cdot 0$ \\
\hline
\end{tabular}

TABLE III - Results of Poisson regression analysis

\begin{tabular}{|c|c|c|c|c|}
\hline Term & df & Estimate & Deviance & $\begin{array}{l}\text { Likelihood ratio } \\
\text { statistic for } \\
\text { addition of } \\
\text { each term } \\
\text { (p value) }\end{array}$ \\
\hline Baseline rate & & $9.4 \times 10^{-5}$ & & \\
\hline Race: Asian $v$ non-Asian & 1 & 0.4468 & $4 \cdot 349$ & $0 \cdot 037$ \\
\hline Yeart & 1 & 0.9796 & $0 \cdot 464$ & 0.496 \\
\hline Race: Asian $\ddagger$ •year & 1 & 1.537 & $4 \cdot 719$ & 0.030 \\
\hline Sex: female $v$ male & $i$ & $1 \cdot 310$ & 0.587 & 0.444 \\
\hline Race: Asian •sex: female & 1 & 0.422 & $3 \cdot 847$ & 0.050 \\
\hline Residual & 150 & & $164 \cdot 9$ & \\
\hline Total & 155 & & 178.9 & . \\
\hline
\end{tabular}

${ }^{\star}$ Estimates presented are of baseline rate and rate ratios respectively, and not model coefficients.

†Year was coded as $1978-81=0 ; 1982-4=1 ; 1985-7=2 ; 1988-90=3$

†Interaction terms are represented by dot between two terms involved.

three cases of diabetes were identified in children of Asian origin, corresponding to an incidence of $3 \cdot 1 / 100000$ per year. By contrast there were 46 cases in non-Asian children in the area during the same period, corresponding to an incidence of $11 \cdot 8 / 100000$ per year (table I). In the last three years of the study (1988-90) there were 12 cases in Asian children (incidence $11 \cdot 7 / 100000$ per year) compared with 31 cases in the non-Asian children (incidence $12 \cdot 0 / 100000$ per year). The increase in incidence among the Asian children over the entire study period was statistically significant, confirming our main hypothesis $\left(\chi^{2}\right.$ for trend $=4.95$, $\mathrm{df}=1, \mathrm{p}=0.026$ ).

There was a significant excess of males among the Asian cases (male to female ratio 1·8:1), which was not observed among the non-Asian cases (male to female ratio $0 \cdot 76: 1$ ) (test for common odds ratio: $\chi^{2}=3 \cdot 81$, $\mathrm{df}=1, \mathrm{p}=0.052$ ) (table II). The time trends for incidence remained unchanged after adjusting for age and sex by using Poisson regression (table III).

\section{Discussion}

The incidence of insulin dependent diabetes in European children is believed to be rising. ${ }^{1213}$ Therefore, Asian families have migrated from an area of low incidence to an area of relatively high and rising incidence. If the cause of childhood diabetes were purely genetic we would expect to see no change in incidence in migratory families. However, if local environmental factors are involved then we would expect a rise in incidence. This is what was found in the present study. The Asian families did not show the rarity of childhood diabetes seen in the Indian subcontinent, but they showed a rising incidence in the first generation of United Kingdom born children. Furthermore, this incidence more than doubled from $4 \cdot 4$ in 1978-84 to $9 \cdot 1 / 100000$ per year in $1985-90$, which was similar in the incidence for non-Asian children in the same area.

It could be argued that the observed increased incidence of diabetes in the Asian children was due to better ascertainment of cases among this ethnic group in the later years of the study. This is unlikely for the following reasons: cases were ascertained from the entire area of the Yorkshire Regional Health Authority (West and North Yorkshire and Humberside) as well as from districts and hospitals surrounding the region; the bulk of the Asian community lives in the centre of Bradford close to the index hospital, and it is unlikely that any of these children would have travelled outside the region for diagnosis and treatment.

Our overall incidence was only two thirds of the $14.9 / 100000$ estimated for Yorkshire in the British paediatric surveillance survey. ${ }^{12}$ This lower rate could be due to a rising incidence as the higher figure comes from 1988 and our data cover 1978-90. In addition, the national study concerned children aged $0-14$ years whereas the present study included children aged 0-16. It is unlikely to arise from faulty ascertainment, although it is possible that Bradford may have an incidence lower than that for the rest of Yorkshire. The Asian diabetic children showed a significant male preponderance as expected from many previous studies of childhood diabetes. The lack of the expected male excess in the non-Asian diabetic children in Bradford may have been due to chance.

In Leicestershire, though diabetes in Asian children is now increasingly recognised, the prevalence was roughly half that of white people $-0.54 v 0.99 / 1000$ although small numbers prevented showing a statistically significant difference between the groups. ${ }^{14}{ }^{15}$ More recent data have also suggested that in the current Leicester City cohort consisting of children born both in and outside the United Kingdom Asian children resident in the city have shown an increasing incidence of diabetes. ${ }^{16}$ The Leicester data and those presented here are not strictly comparable as the latter consist solely of United Kingdom born children of Asian immigrant parents. The Bradford Asian community is largely from Pakistan whereas that in Leicester has a sizable component which has migrated via east Africa. However, both sets of data support each other in suggesting a rising incidence of diabetes in Asian children. In the Coventry diabetes study, which compared the characteristics of insulin dependent diabetic patients between Asians and white people, no Asian case was identified with an onset below 19 years of age, possibly because of small numbers. ${ }^{17}$

There is difficulty in accurately comparing the incidences for Asian children born in Bradford and those born in Pakistan and India. This is because there have been virtually no systematic incidence studies of the condition in those countries. Childhood diabetes is said to be extremely rare there, ${ }^{9}$ although one cannot exclude incomplete ascertainment of acute onset cases without access to subsequent medical care. Circumstantial evidence that the condition is rare in India and Pakistan comes from the fact that in the larger cities with major teaching centres - for example, Karachifew cases of childhood diabetes are known (A S Shera, personal communication) whereas in Leeds (total population roughly 750000 ) there were about 120 cases in patients under the age of 16 years attending two designated specialist clinics.

At present most migrant families marry within their 
own group and so the genetic background of first generation children can be presumed to be similar to that of their counterparts in the Indian subcontinent. A previous study of Asian children with insulin dependent diabetes in West Yorkshire found that they have the typical genetic susceptibility factors HLADR3 and DR4. ${ }^{10}$ Thus on this genetic background susceptible individuals seem to be exposed to an environmental triggering factor(s) to which they are not exposed before migration.

What is the nature of this environmental effect? Two types of effect have been considered previously: diet and viral infections. Again one can make a presumption that dietary factors are unlikely as most Asian families in Bradford have maintained their usual diet, although methods of preserving food may have changed. Viral infections may be more likely. Either these children are now being exposed to new agents which are uncommon in India and Pakistan or they are being exposed to viruses in a different way-for example, at a different age. Climatic conditions may be important as childhood diabetes seems rare in hot countries but is increasingly common in cooler northern European countries.

In conclusion, this unique transmigratory population has moved from an area of extremely low incidence of childhood diabetes to an area with a relatively high incidence and children in this community have shown a corresponding increase in disease incidence, now matching that of the indigenous population, thereby providing evidence of an aetiological environmental effect.

We thank Miss S H Benson, Professor A Samad Shera (Karachi), Dr H B Chandalai (Bombay), Dr P A McKinney, and Dr A Franks for advice; Mr M Barrett of Bradford District Metropolitan Council, for demographic data; and
Mrs M E Smith for preparing the manuscript. This work was supported by project grant LW 219 of the Yorkshire Regional Health Authority. AS and RC are supported by the Leukaemia Research Fund.

1 Walker A, Cudworth AG. Type 1 (insulin-dependent) diabetic multiplex families: mode of genetic transmission. Diabetes 1980;29:1036-9.

2 Barnett AH, Eff C, Leslie RDG, Pyke DA. Diabetes in identical twins: a study of 200 pairs. Diabetologia 1981;20:87-93.

3 Reijonen H, Ilonen J, Michelson B, Akerblom HK. HLA-DQ beta-chain restriction fragment length polymorphism as a risk marker in type 1 (insulin-dependent) diabetes mellitus: a Finnish family study. Diabetologio 1990;33:357-62.

4 Diabetes Epidemiology Research International. Preventing insulin-dependent diabetes mellitus: the environmental challenge. $B M F$ 1987;295:479-81.

5 Toniolo A, Federico G, Manocchio I, Onodera T. Aetiology and pathogenesis of type 1 diabetes: viruses. In: Besser GM, Bodansky HJ, Cudworth AG, eds. Clinical diabetes. Philadelphia: Lippincott, 1988:10.1-10.20.

6 Helgason T, Jonasson MR. Evidence for a food additive as a cause of ketosisprone diabetes. Lancet 1981;ii:716-20.

7 Marmot G. General approaches to migrant studies: the relation between disease, social class and ethnic origin. In: Cruickshank JK, Beevers DG, eds. Ethnic factors in health and disease. London: Wright, 1989:12-7.

8 Gamble DR. Aetiology and pathogenesis of type 1 diabetes: epidemiology. In Besser GM, Bodansky HJ, Cudworth AG, eds. Clinical diabetes. Philadelphia: Lippincott, 1988:7.1-7.8.

9 Menon PSN, Viramani A, Shah P, Raju R, Sethi AK, Sethia S, et al. Childhood onset diabetes mellitus in India: an overview. Intermational foumal of Diabetes in Developing Countries 1990;10:11-6.

10 Bodansky HJ, Beverley DW, Gelsthorpe K, Saunders A, Bottazzo GF, Haigh D. Insulin dependent diabetes in Asians. Arch Dis Child 1987;62:227-30.

11 Payne RW, Lane PW, Ainsley AE, Bicknell KE, Digby PGN, Harding SA, et al. Genstat 5 reference manual. Oxford: Clarendon Press, 1987.

12 Metcalf MA, Baum JD. Incidence of insulin-dependent diabetes in children aged under 15 years in the British Isles during 1988. BM7 1991:302:443-7.

Bingley PI Crale EAM. Rising incidence of IDDM in Europe. Diaberes Core 1989;12:289-95.

14 Samanta A, Burden AC, Hearnshaw JR, Swift PGF. Diabetes in Asian children. Lancet 1990;335:1341.

15 Samanta A, Burden AC, Jones GR, Woodlands IG, Clarke M, Swift PGF, et al. Prevalence of insulin-dependent diabetes mellitus in Asian children. Diabetic Med 1987;4:65-7.

16 Burden AC, Samanta A, Chaunduri KH. The prevalence and incidence of insulin-dependent diabetes in white and Indian children in Leicester city (UK). International fournal of Diabetes in Developing Countries 1990;10:8-10. 17 Simmons D. Prevalence and age of onset of type 1 diabetes in adult Asians in the Coventry diabetes study. Diabetic Med 1990;7:238-40.

(Accepted 19 February 1992)
Division of Epidemiology and Public Health, School of Health Care Sciences, Newcastle upon Tyne NE2 4HH

Rajinder S Bhopal, professor of epidemiology and public health

\section{Department of}

Mathematics, School of Engineering, Computing, and Mathematical Sciences, University of Lancaster, Lancaster LA1 4YF

Peter Diggle, professor of statistics

Barry Rowlingson, research associate

Correspondence to:

Professor Bhopal.

BMF 1992;304:1022-7

\title{
Pinpointing clusters of apparently sporadic cases of legionnaires' disease
}

\author{
Rajinder S Bhopal, Peter Diggle, Barry Rowlingson
}

\section{Abstract}

Objectives-To test the hypothesis that many non-outbreak cases of legionnaires' disease are not sporadic and to attempt to pinpoint cases clustering in space and time.

Design-Descriptive study of a case series, 1978-86.

Setting -15 health boards in Scotland.

Patients-203 probable cases of non-outbreak, non-travel, community acquired legionnaires' disease in patients resident in Scotland.

Main measures-Date of onset of disease and postcode and health board of residence of cases.

Results-Space-time clustering was present and numerous groups of cases were identified, all but two being newly recognised. Nine cases occurred during three months within two postcodes in Edinburgh, and an outbreak was probably missed. In several places cases occurred in one area over a prolonged period-for example, nine cases in postcode districts G11.5 and G12.8 in Glasgow during five years (estimated mean annual incidence of community acquired, non-outbreak, non-travel legionnaires' disease of 146 per million residents $v$ 4.8 per million for Scotland). Statistical analysis showed that the space time clustering of cases in the Glasgow and Edinburgh areas was unusual $(p=0.036$, $p=0.068$ respectively).

Conclusion-Future surveillance requires greater awareness that clusters can be overlooked; case searching whenever a case is identified; collection of complete information particularly of date of onset of the disease and address or postcode; ongoing analysis for space-time clustering; and an accurate yet workable definition of sporadic cases. Other researchers should re-examine their data on apparently sporadic infection.

\section{Introduction}

Legionnaires' disease is an environmentally acquired bacterial pneumonia associated with explosive outbreaks. However, as indicated by surveillance data in England and Wales, ${ }^{1}$ the United States, ${ }^{2}$ and Scotland, most cases are not linked with outbreaks, and for these the source of infection is rarely identified. ${ }^{46}$ Such cases are commonly referred to as sporadic cases. ${ }^{267}$ Strictly speaking, therefore, they should be single cases with no association in time and space with other cases. However, we can find no published definition of sporadic infection with legionnaires' disease or discussion of the measures required to show that such cases are truly sporadic. By default, cases which are not part of identified outbreaks are usually classified as sporadic.

Present advice is to undertake detailed epidemiological and environmental investigations for cases related to outbreaks, but not for sporadic cases. Usually, detailed investigation is started when two 